\title{
Unidades léxicas abreviadas del lenguaje médico actual utilizado en la prensa escrita
}

Abbreviations of the modern medical language used in the written press

ANNA KOVRIGINA

UNIVERSIDAD ESTATAL LOMONÓSOV DE MOSCÚ, RUSIA

ORCID: https://orcid.org/0000-0001-8490-0425

RESUMEN: El objetivo del presente artículo es estudiar el potencial lingüístico y creativo de unidades léxicas creadas a base de palabras o sintagmas abreviados mediante el análisis del lenguaje de la prensa escrita. El estatus lingüístico de las abreviaciones no es fijo, van acomodando su configuración externa, pronunciación y propiedades morfosintácticas a las palabras naturales del idioma. Los rasgos que testimonian la adaptación de las abreviaciones son su lexicalización y acomodación gráfica y fónica, pérdida de motivación semántica, participación activa en los procesos derivativos. La variedad en el aspecto grafemático y morfológico (oscilaciones con respecto al género, formación del plural, dificultad para distinguir las categorías gramaticales de sustantivo y adjetivo, uso de guion, mayúsculas o minúsculas) tiene relación, por un lado, con el creciente y continuado uso de las unidades abreviadas en el lenguaje y con ausencia de normas de uso convencionales, por otro. La frecuencia y amplitud de uso de las abreviaciones por razones de comodidad y economía lingüística concurre con la búsqueda de efectos estilísticos, por lo que su presencia es amplia en los llamados géneros de opinión.

Palabras clave: abreviación, sigla, acrónimo, acortamiento, periódico.

ABSTRACT: The purpose if this paper is to explore the linguistic and creative potential of lexical units resulting from the compression of words or phrases, by analyzing the language of the written press. The linguistic status of the abbreviated units is not uncontroversial, they are accommodating their external configuration, pronunciation and morphosyntactic features to common words. The adaptation of the abbreviations takes place through their lexicalization, 
semantic demotivation, phonological and spelling accommodation, active participation in word formation. Phono-graphemic and morphological variation (with respect to the gender, plural forms, grammar categories of noun and adjective, hyphenation, use of capital or small letters) is related, on the one hand, to the continuous and growing use of the abbreviations in the language and, on the other, to the absence of the conventional usage norms. High frequency and widespread use to save space and effort come together with the search of stylistic effects, explaining why the abbreviations are widely present in feature articles.

Key words: abbreviation, initialism, acronym, clipping, newspaper.

\section{INTRODUCCIÓN}

El lenguaje de la prensa está muy predispuesto a los cambios y se caracteriza por una potente capacidad de recoger los neologismos que aparecen en la lengua general y los lenguajes de especialidad. Teniendo en cuenta que la lengua es un hecho social, es natural que el nivel más inmediatamente afectado sea el léxico. Las causas del cambio siempre son las mismas: las necesidades de la comunicación, que, a su vez, están relacionadas con los cambios en la sociedad. Como explica F. Rodríguez González, se trata de neologismos «puestos inmediatamente en circulación y difundidos con gran eficacia, si designan nuevos referentes de utilidad pública» (Rodríguez González, 2019: 291).

Dada la dimensión dramática y los estragos que ha causado la pandemia del COVID-19 en todo el mundo y España en particular, los protagonistas de los textos periodísticos son ahora los datos, gráficos y, sobre todo, el léxico especializado del campo de la medicina y ciencias de la salud.

La necesidad de dar a conocer dosis masivas de información y explicar los pormenores de la nueva enfermedad en un espacio periodístico reducido invita a hacer uso de la economía gráfica y conduce a que los términos médicos a menudo aparecen en su forma abreviada. Existen varios tipos de abreviaciones, unidas por el objetivo común de ahorrar un esfuerzo al emisor y, dependiendo del grado de su divulgación y empleo en la lengua general, también un esfuerzo al receptor. Salta a la vista que se está incorporando un lenguaje científico a los diarios como nunca antes, haciendo uso de la capacidad creadora del lenguaje, intentando asimilar las abreviaciones, darles nueva vida y hacer que cobren existencia y valor en el conjunto de unidades del léxico español. Precisamente por esta razón merece especial atención el estudio del potencial lingüístico y creativo de nuevas unidades léxicas creadas a base de sintagmas abreviados y asimiladas a un ritmo vertiginoso por el lenguaje de la prensa escrita.

\section{TRABAJOS RELACIONADOS Y PROPUESTA}

La formación de palabras en español siempre ha sido el centro de importantes estudios teóricos y son muchos los investigadores que se han ocupado de este tema tan amplio y complejo (Alvar Ezquerra y Miró Domínguez, 1983; Lang, 1992; Alvar Ezquerra, 1996; Hernando Cuadrado, 1996; Almela Pérez, 1999; Martín Camacho, 2007). 
Varios aspectos del lenguaje de los medios de comunicación han recibido atención desde la perspectiva lingüística: Alarcos Llorach, 1977; Muñiz Chacón, 1990; Romero Gualda, 1993; Hurtado González, 2003; Aleza Izquierdo, 2006, Grijelmo, 2008.

A pesar de todo el trabajo realizado hasta hoy, el fenómeno lingüístico de la abreviación se nos presenta como vagamente definido y poco estudiado de forma sistemática. Nos enfrentamos, principalmente, con la ausencia de un acuerdo unánime sobre la denominación más idónea de este léxico específico, su taxonomía y funcionamiento en diferentes tipos de discursos profesionales. Por un lado, parece que los estudios llevados a cabo en torno a los distintos tipos abreviativos no se sustentan en una base criterial única y estandarizada, y aplican una diversidad de términos a los mismos fenómenos lingüísticos. Por otro lado, las abreviaciones son casi siempre creaciones innovadoras que gozan de una gran libertad de funcionamiento en la lengua española, por lo que están en continuo movimiento, sufren diferentes mutaciones y evolucionan, dando lugar a nuevas abreviaciones que siguen unos patrones desconocidos hasta el momento de la aparición, lo que crea confusión entre los investigadores, y hace sumamente difícil la tarea de delimitar los distintos tipos que conforman el concepto de "abreviación" en español. Dicho esto, es preciso delimitar y aclarar los términos que utilizaremos en el presente artículo y los procedimientos abreviativos que vamos a estudiar (véase fíg. 1).

\section{Figura 1. Esquema clasificatorio de unidades léxicas abreviadas}

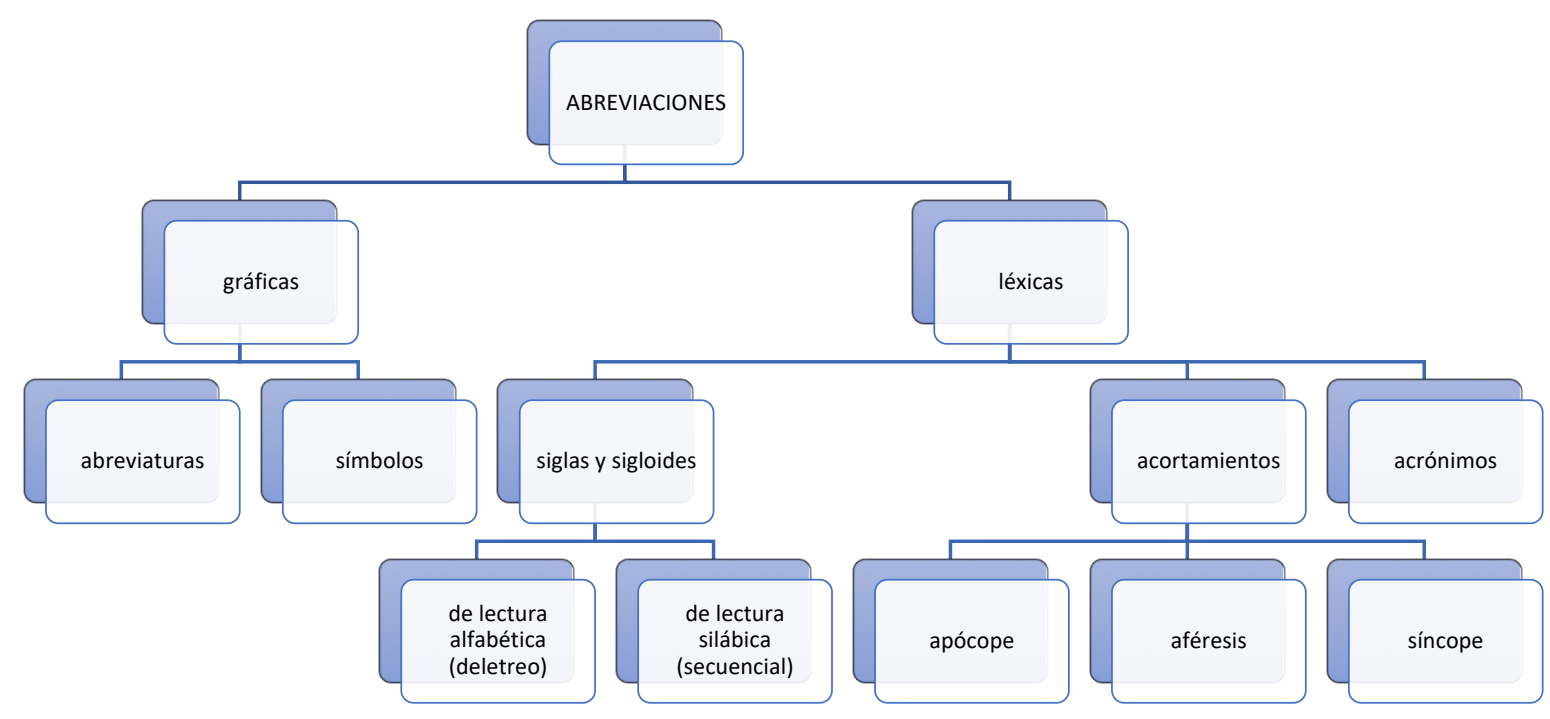

Partimos del concepto amplio de "abreviación" como término genérico, tal y como lo recoge la versión de consulta en línea de la 23. ${ }^{a}$ edición del Diccionario de la Lengua española:

1. Acción y efecto de abreviar.

2. Procedimiento de reducción de una palabra o de una expresión compleja mediante la supresión de determinadas letras o sílabas.

3. Palabra o representación gráfica formada por abreviación. Acrónimos, acortamientos, abreviaturas y siglas son abreviaciones.

El primer grupo, las abreviaciones gráficas, no entran en este estudio, ya que se utilizan exclusivamente en el lenguaje escrito y en el habla se reproduce la palabra 
completa que representan. Dentro de este grupo de distinguimos abreviaturas ${ }^{1}$ (Sr. $<$ señor) y símbolos ( $\mathrm{km}<$ kilómetro).

El segundo grupo, las abreviaciones léxicas, realizan fonéticamente su forma reducida en la lengua oral. Esta es la principal diferencia de las abreviaciones gráficas que carecen de su propia forma fónica y reproducen la palabra o frase inicial completa: son una «mera representación gráfica» de ésta (Rodríguez González, 2019: 271).

Las abreviaciones léxicas, a su vez, se subdividen en acrónimos, siglas, sigloides y acortamientos en función del procedimiento formativo que se utilice. Es una subdivisión bastante formal y aproximada, que nos sirve para los objetivos del presente estudio.

\section{METODOLOGÍA}

Para describir e ilustrar los rasgos relacionados con la pronunciación y ortografía de las abreviaciones en español, así como sus propiedades semánticas, morfosintácticas y estilísticas, hemos establecido un procedimiento de dos etapas: recolección de datos y análisis de datos. La primera etapa incluye la recopilación de las abreviaciones e información sobre su uso en contextos pertinentes. El trabajo con las fuentes escritas de la prensa digital de España (versiones digitales de El País, El Mundo, ABC, 20 minutos) se realizó en el período comprendido entre febrero y julio de 2020. Hemos anotado 121 abreviaciones del lenguaje médico usado en la prensa escrita.

El corpus resultante engloba las abreviaciones utilizadas en el idioma español moderno de la prensa de calidad. La frecuencia léxica no se ha tenido en cuenta, ya que el presente estudio es un análisis descriptivo y no busca proporcionar datos estadísticos. El corpus se entiende como un instrumento que proporciona datos actuales sobre el uso real de unidades léxicas abreviadas y brinda una base empírica que permite determinar regularidades de funcionamiento de las abreviaciones médicas en el discurso periodístico.

La segunda etapa consiste fundamentalmente en el análisis lingüístico de los principales tipos abreviativos, sus características y funciones dentro de la oración, usos habituales y estéticos, con especial atención a los préstamos, ilustrados con los ejemplos más representativos.

\section{RESULTADOS}

\subsection{ACRÓNIMOS}

\subsubsection{Concepto y definición}

El concepto de "acrónimo" necesita ser precisado, puesto que los investigadores discrepan a menudo en cuanto a su denominación, definición, procedimiento de formación, etc. Por lo general, los estudiosos tienden a considerar que el acrónimo se compone de fragmentos de dos o, con menos frecuencia, de tres palabras unidas en un solo lexema indivisible como, por ejemplo, en farmaindustria ( $<$ farmacológica + industria). Si se abrevia la primera palabra que forma parte del sintagma, debe ser la parte inicial del significante; si se abrevia la unidad final, se usa su fragmento también final (Casado Velarde, 1999: 5085).

El estudio sistematizado de la acronimia tiene un gran significado teórico y práctico para determinar el estatus de los acrónimos y el papel que desempeñan en el sistema de la lengua española, ya que, a pesar de ser relativamente nuevo, este particular

\footnotetext{
${ }^{1}$ El término "abreviatura" se utiliza en la bibliografía con un significado más general, como sinónimo de "abreviación", pero en este artículo es un término de uso más bien restringido.
} 
fenómeno ya está ampliamente representado en la lengua e incluso tiene ciertas regularidades de carácter general.

\subsubsection{Tipología}

Según nuestras indagaciones, y al analizar las muestras encontradas en el lenguaje médico usado en la prensa escrita, se hace patente la problemática en torno a la formación de acrónimos, donde se utilizan conjuntamente los mecanismos lexicogenésicos de reducción y composición. La peculiaridad de los acrónimos consiste en que son el resultado combinado de los procesos de acortar y recomponer, lo que algunas veces plantea el problema de distinción entre:

1) combinación de dos morfemas léxicos abreviados como en coronacrisis $(<$ coronavirus + crisis $)$, coronabonos $(<$ coronavirus + bonos $)$, farmaindustria $(<$ farmacológica + industria);

2) elementos compositivos de procedencia culta, griega o latina, que se combinan

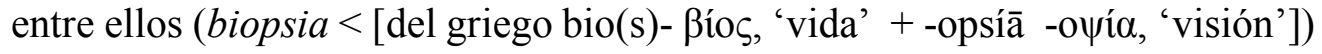
o se unen a otros términos en castellano (biodiversidad ( $<$ bio + diversidad).

Los ejemplos del primer tipo son escasos, mientras que los del segundo, al contrario, abundan extensamente en el lenguaje médico usado en la prensa digital. A continuación, se muestran algunos ejemplos:

- bio (del griego bio(s)- ßíos, 'vida'): bioseguridad (El Mundo, 02/06/2020), bioingeniería (El País, 03/06/2020), bioestadísticos (El País, 03/06/2020), biomédico (El País, 27/02/2020), biotecnología, biotecnológicas (20 minutos, 24/03/2020)

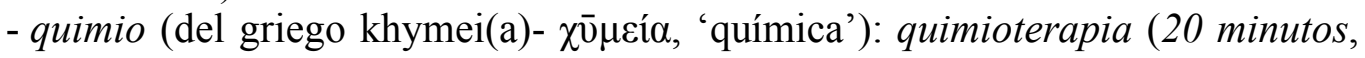
10/06/2020), quimioprevención (El Mundo, 21/05/2020),

- hemo (del griego haim(ato)- $\alpha \tilde{i}-\mu \alpha /-\mu \alpha \tau o \zeta$, 'sangre': hemodonación, hemoterapia, hemovigilancia $(A B C, 13 / 06 / 2020)$,

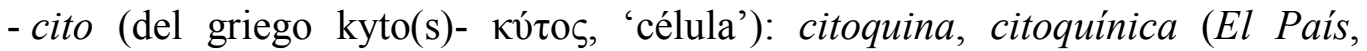
08/04/2020), leucocitos, granulocitos, linfocitos $(A B C, 18 / 06 / 2020)$

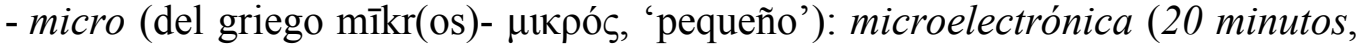
24/03/2020)

- nano (del griego nan(os)- vóvos, 'enano'): nanotecnología, nanobiotecnológicas, nanociencia (20 minutos, 24/03/2020), nanopartículas (20 minutos, 12/04/2020)

- radio (del latín radi(um)-, 'palo', 'rayo', 'radio'): radiografía (El País, 03/06/2020)

- fago (del griego -phag(os) -

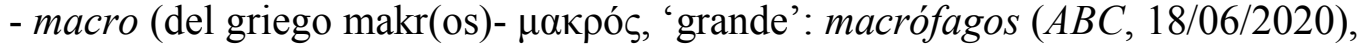

- filo (del griego [phil(os)- píd-oc/-ov, 'con afinidad por']): neutrófilos $(A B C$, 18/06/2020)

En este caso se puede hablar de un grupo numeroso de palabras de lenguaje específico formadas con las bases compositivas cultas prefijas o sufijas que convierten la palabra creada en un acrónimo desde el punto de vista etimológico. Según se explica en la Nueva gramática de la lengua española, «la etimología de una voz traza su historia, independientemente de si la estructura que presenta está o no activa entre los esquemas morfológicos de la lengua» (Nueva gramática de la lengua española, 2010: 174).

Esta hipótesis se ve reforzada por los planteamientos de los lingüistas modernos: Martín Camacho (Martín Camacho, 2007) también incluye el acrónimo biónica $(<$ bio + electrónica) en su lista de acrónimos de lenguaje científico; Estornell Pons define los 
neologismos por acronimia como «combinación de un tema» y un segmento de un vocablo, entendiendo por temas los denominados prefijos y afijos cultos (en Aleza Izquierdo, 2006: 275). Encontramos una descripción exhaustiva de dicho fenómeno en (Casado Velarde, 1999: 5089), donde presenta series acronímicas formadas por «temas de compuestos cultos»».

Con todo, es difícil determinar si se trata de un procedimiento de derivación por adición de afijos o de composición por acronimia que proviene de la fusión de segmentos de palabras truncadas o, incluso, de composición por aglutinación (Hernando Cuadrado, 1996). El Diccionario de la lengua española trata esos cultismos abreviados como «elementos compositivos», pero vemos que poseen distintos grados de integración en el sistema de la lengua: algunos elementos se han lexicalizado más, hasta han llegado a funcionar de manera independiente en la lengua como acortamientos (bio, quimio, fago, radio), otros como -cito/cito- o -filo carecen de significado propio, adquiriéndolo solo en combinaciones con otras bases léxicas.

\subsubsection{Caracterización morfosintáctica}

En lo que respecta al primer tipo de acrónimos ${ }^{2}$, por lo general, es difícil determinar dónde se va a efectuar el corte de las bases léxicas para formar un nuevo acrónimo y cómo se combinarán los morfemas abreviados. De hecho, Martín Camacho define el procedimiento de formación de acrónimos como no morfemático puesto que «el modo en que se seleccionan los fragmentos componentes no está condicionado por la estructura morfémica de la palabra» (Martín Camacho, 2007: 252). Un ejemplo muy característico de un acrónimo de este tipo sería el acrónimo de procedencia extranjera remdesivir. Como señala el Diccionario Merriam Webster, está formado por un elemento -vir, abreviado de "virus", rem- de un origen indeterminado y carente de significado de acuerdo con las prescripciones del Consejo de Nombres Adoptados de los EE. UU. (U.S. Adopted Names Council) para los nombres de medicamentos genéricos; y -desi-, que es un interfijo que denota un análogo de adenosina.

De modo semejante se puede trazar el mecanismo de formación de los nombres de otros medicamentos antivirales: zanamivir < zan- (origen indeterminado) + -ami(interfijo que denota un inhibidor de neuraminidasa) + -vir (abreviado de "virus"); ritonavir < rito- (abreviado y transformado de "proteasa") + -navir (abreviado de "antiviral"); lopinavir < lopi- (origen indeterminado) + -navir (abreviado de "antiviral") $(A B C, 12 / 03 / 2020)$.

Con los derivados acrósticos de la palabra "coronavirus" es más fácil seguir el patrón de formación del acrónimo compuesto por un abreviamiento por apócope "corona" en combinación con otras palabras pertenecientes al léxico común: coronacrisis ( $\mathrm{El}$ Mundo, 02/06/2020), coronabonos (ABC, 25/03/2020).

Como habrá podido observarse, aunque la mayoría de acrónimos pertenece a la categoría gramatical de sustantivos, también hay algunos adjetivos. Además, hemos podido detectar un verbo e, incluso, un participio, pertenecientes al grupo de acrónimos etimológicos:

- Requena recomienda «por ahora, que los criopreservemos $[\ldots]\rangle(<$ crio [del griego kryo- $\kappa \rho v ́ o \varsigma$ 'frío glacial', 'hielo'] + preservar) (20 minutos, 16/03/2020)

- [...] protege de cualquier partícula o patógeno aerotransportados $(<$ aero [del griego āero(s)- àćpos 'aire'] + transportado) (El País, 11/06/2020).

\footnotetext{
${ }^{2}$ Utilizando este término en su acepción más estricta detectada en la bibliografía.
} 
En la mayoría de los casos el género y número del acrónimo se determinan según el morfema flexivo del lexema resultante de acuerdo con las reglas del español: el remdesivir, la fagocitosis, los coronabonos. Normalmente, el morfema flexivo del núcleo semántico es al mismo tiempo el morfema flexivo del nuevo lexema y sirve para marcar su género.

\subsubsection{Uso}

Los acrónimos encontrados en los géneros periodísticos informativos, como toda innovación léxica, se utilizan por la necesidad de nombrar un objeto o fenómeno concreto que no existía anteriormente. Sin embargo, su uso se ve motivado también por el deseo de captar la atención del lector con una forma novedosa e interesante, por eso a menudo aparecen en cursiva o entrecomillados para destacar su novedad.

Por otro lado, en la prensa digital se encuentran muestras del uso de acrónimos en los artículos de opinión, un género que se caracteriza por un lenguaje ingenioso, pulido y muy original, y una combinación de argumentos lógicos con recursos expresivos o estilísticos. En este contexto lingüístico la principal función de los acrónimos es añadir un valor humorístico, irónico o peyorativo-despectivo, como se puede observar en los siguientes ejemplos:

1) La podemia (< Podemos + pandemia) y la PSOE siguen profesando una fe sorprendente en la fijación oficial de precios [...] $(A B C, 24 / 04 / 2020)$;

2) Los pandemitas (< pandemia + podemita [de Podemos]) $(A B C, 23 / 04 / 2020)$;

3) $[\ldots]$ entre otras razones, porque forman parte del mismo magma que promueve las ideícas pandemitas $\left(<\right.$ pandemia + podemita) ${ }^{3}(A B C, 23 / 04 / 2020)$.

El particular efecto humorístico de estas creaciones acronímicas ocasionales se hace más patente debido a su semejanza formal y fuerte asociación con las palabras que las han motivado: podemia - pandemia, pandemitas - podemitas. La diferencia entre las dos palabras es tan insignificante que puede parecer un error accidental del autor, multiplicando así el efecto deseado del enunciado deliberadamente despectivo e irónico.

Los acrónimos creados con fines lúdicos constituyen, sin duda, un recurso ocasional y de carácter efímero. Se crean y se usan por un solo autor para producir el efecto humorístico y se olvidan después, salvo si gozan de aceptación social en el habla y se asientan en la lengua, como ha pasado con farmaindustria $(<$ farmacológica + industria) y algunos pocos ejemplos más.

\subsection{ACORTAMIENTOS}

\subsubsection{Concepto y tipología}

Los acortamientos o truncamientos son un fenómeno léxico muy peculiar del idioma español. La cuestión de tratamiento científico de los acortamientos no se ha planteado con frecuencia en la literatura lingüística española, dado que los investigadores examinaban los acortamientos solo como parte de la jerga juvenil utilizada por un grupo limitado de personas y, por lo tanto, carente de interés.

Según el procedimiento de formación empleado, existen tres tipos de acortamientos: apócopes (se pierde el final de la palabra), aféresis (se suprime el comienzo de la palabra) y síncope (se corta la parte mediana de la palabra) (véase la Figura 1). Según nuestras indagaciones, en los artículos digitales dedicados a los temas

\footnotetext{
${ }^{3}$ Cabe destacar, además, el valor atributivo del acrónimo en el ejemplo (3) que pertenece a la categoría gramatical de adjetivo.
} 
médicos se da un predominio de apócopes. Hemos detectado solo una muestra de síncope: corticoides < corticosteroides (El País, 08/04/2020) y una de aféresis: fago < bacteriófago (El Pais, 27/02/2020).

\subsubsection{Caracterización morfosintáctica}

Por razones morfofonológicas, se acortan con más frecuencia los sustantivos, mientras que las muestras de adjetivos acortados son muy escasas en el lenguaje científico, caracterizado por el uso abundante de términos nominativos que designan objetos y conceptos científicos. El hecho de que los sustantivos se abrevien tan fácilmente para agilizar el lenguaje puede explicarse por la gran diversidad morfemática del sustantivo y su independencia funcional de las demás categorías gramaticales, mientras que los verbos y adjetivos, debido a la regularidad y estabilidad gramatical de sus flexiones, pueden tener solo unas desinencias estrictamente determinadas, que, además, tienen función diferenciadora de significado.

A diferencia de los acrónimos, el mecanismo de acortamiento es morfemático, es decir, la localización del corte sigue la estructura morfemática y normalmente permanece intacto solo el primer morfema, y se eliminan los demás. El principio fonológico (facilidad de pronunciación) desempeña un papel muy importante en la formación de apócopes, facilitando también la localización de la segmentación de acuerdo con la estructura silábica de la palabra, es decir, las sílabas completas no se dividen en la mayoría de los casos.

Al haber explorado los acortamientos del lenguaje médico, podemos concluir que el modelo bi- o trisílabo y la terminación en una vocal son las características más comunes y frecuentes de las apócopes españolas (fisio < fisioterapia, fisioterapeuta, quimio < quimioterapia, pulsi< pulsioxímetro), a diferencia, por ejemplo, de las apócopes inglesas que son monosílabas por lo general y terminan en una consonante: lab, gov, doc.

Las abreviaciones formadas por acortamiento presentan un grado de lexicalización muy alto. Basándonos en el corpus seleccionado, destacamos que los acortamientos utilizados en el lenguaje médico, en su mayor parte, mantienen la categoría gramatical y el género de la palabra primitiva: la quimio, el otorrino. Hemos encontrado solo una excepción: el préstamo "combo" (del inglés "combo", acortado de "combination", 'combinación'), anglicismo en función de adjetivo usado sin traducción ni modificación, acompañado de un artículo de género masculino: el 'combo' azitromicina e hidroxicloroquina (El Mundo, 21/05/2020). Se puede observar cómo el uso del anglicismo influye también en la estructura sintáctica de la frase española, que pierde la preposición "de" en el complemento preposicional por asociación con el uso original en el inglés.

En el material investigado nos ha llamado la atención el uso de estructuras similares a las aposiciones de tipo "pájaro mosca" o "ciudad jardín", bien arraigadas en la lengua castellana:

- Cosmética Bio: un negocio con esencia (El Mundo, 13/05/2020);

- Este tipo de hierro (llamado hierro no hemo) se asimila muy mal ( $A B C$, 17/03/2020).

Se trata del empleo de acortamientos sustantivos con valor adjetivo, cuando un sustantivo acortado se encuentra en posposición al sustantivo que cumple el papel del núcleo semántico del sintagma y lo modifica como adjetivo, pero no varía en género ni 
número. Parece un fenómeno cuya categorización no es nada clara, por lo que merece ser estudiado con atención ${ }^{4}$.

\subsubsection{Uso}

Cabe mencionar que con el uso de los acortamientos en la prensa se busca un doble objetivo. En primer lugar, se utilizan cuando el periodista cita literalmente las palabras de una persona entrevistada y así un acortamiento propio de la lengua hablada penetra en el texto de un artículo: «También les llevamos al médico con un servicio de transporte y se les pautan ejercicios con el fisio y los psicólogos», cuenta a $A B C$ la directora del servicio, Ana Cruz $(A B C, 10 / 05 / 2020)$.

No obstante, interesa más fijarse en aquellos acortamientos que se usan como un recurso estilístico con el fin de intensificar el tono informal del artículo, lo que acorta la distancia entre el autor y el lector:

1) ¿Puedo ir al fisio o a un centro de estética sin cita previa? (El Mundo, 10/05/2020);

2) La emotiva sorpresa de unos padres: «Hoy es mi última quimio» $(A B C$, 28/05/2020);

3) La planta de medicina interna se está empezando a llenar, después de la mía y la de neumo (< neumología) (El País, 03/06/2020);

4) Me puse el pulsi, estaba desaturando (El País, 03/06/2020);

5) Todo el mundo se ha puesto a trabajar en el tema, ya sea cirujano de plástica, rehabilitador, cardiólogo, endocrino $(<$ endocrinólogo) [...]. (El País, 03/06/2020).

En el ejemplo (1) se cita un artículo en formato pregunta-respuesta que busca acercamiento al lector y facilitación de la comprensión y búsqueda de respuestas a sus preguntas; en el ejemplo (2) se trata de un artículo escrito con intención afectiva y valor emocional; en los ejemplos (3), (4) y (5) se muestran extractos del diario del médico infectólogo contado en primera persona, destacando el valor altamente emocional del artículo.

Los testimonios arriba analizados demuestran que el amplio uso en la prensa propicia el desplazamiento del léxico profesional especializado al estilo periodístico y registro coloquial, con el mismo significado básico de su forma plena, pero con connotaciones especiales debidas a la reducción de su cuerpo fónico por razones de comodidad y economía lingüística.

\subsection{SIGLAS Y SIGLOIDES}

\subsubsection{Concepto y definición}

Indudablemente las siglas son «el tipo más productivo y frecuente de abreviaciones» (Rodríguez González, 2019: 292) que podemos observar en el lenguaje médico utilizado en la prensa.

En la clasificación de Martínez de Sousa (1978: 32), las siglas se dividen en propias e impropias según el método de su formación. Se consideran siglas propias las

\footnotetext{
${ }^{4}$ Rodríguez González y Sánchez Fajardo (2018) en su extenso artículo dedicado a la variable morfología de los acortamientos describen adjetivos acortados agramaticales que no varían en plural y singular: las pelis porno o las chicas provo. Definen este fenómeno como "agramaticalidad relacionada con el número" (number-related ungrammaticality). Sin embargo, en nuestro caso no se trata de adjetivos, sino de sustantivos acortados.
} 
formaciones léxicas constituidas por una secuencia de grafemas iniciales de un sintagma nominal originario: SEMI $<$ S(ociedad) E(spañola de) M(edicina) I(nterna). Además, son propias las siglas que incluyen las letras iniciales de cada una de las bases léxicas de la palabra compuesta: ARN < á(cido) r(ibo)n(ucleico). La abreviación alcanza aquí su mayor nivel, ya que al lector se le invita a descubrir el significado de la creación neológica, no a través de unas sílabas, como en el caso de los acrónimos, sino a través de unas letras, detrás de las cuales se esconden palabras constituyentes de una secuencia sintáctica.

Las siglas impropias, también llamadas sigloides o siglónimos, incluyen en su cuerpo más grafemas, aparte de la inicial, en búsqueda de la comodidad fonológica: COVID < en inglés, co(rona)vi(rus) d(isease). A veces las preposiciones y conjunciones y otros grafemas también pueden trascender a la sigla, representándose con letras mayúsculas o minúsculas: CPNM (carcinoma pulmonar no microcítico), CoV (coronavirus). Parece ya aceptada la definición de los sigloides propuesta por el lingüista uruguayo A. Rosell: «siglas aparentes, en las que se han utilizado términos secundarios, omitido fundamentales, o no se ha respetado el principio primario de tomar de los vocablos solo la letra inicial» (Rosell, 1967: 34).

Aunque no se trate de siglas propiamente dichas, los sigloides se incluirán en el análisis en el presente apartado por presentar básicamente las mismas características semánticas, morfológicas y sintácticas y entrar en las mismas relaciones paradigmáticas que las siglas. La única diferencia reside en el plano gráfico y fónico (todos los sigloides son creaciones de lectura silábica por ser la comodidad fónica el principal motivo de su aparición).

\subsubsection{Tipología semántica}

Proponemos la siguiente clasificación de las siglas obtenidas como muestras durante el análisis del lenguaje médico empleado en los periódicos digitales de España. Hemos utilizado como base de clasificación las características semánticas similares, que nos han permitido dividir las siglas en grupos de lexemas de distinta naturaleza conceptual.

1. Sustantivos propios

1.1. Nombres de los organismos oficiales internacionales públicos y privados: OMS (Organización Mundial de Salud), EASA (Agencia Europea de Seguridad Aérea), CDC (en inglés, Center for Disease Control and Prevention [Centro para el Control y Prevención de Enfermedades]);

1.2. Nombres de los organismos oficiales nacionales públicos y privados: COFM (Colegio Oficial de Farmacéuticos de Madrid), AEMPS (Agencia Española de Medicamentos y Productos Sanitarios), CSIC (Consejo Superior de Investigaciones Científicas).

2. Sustantivos comunes

2.1. Nombre del virus y/o la enfermedad que causa: COVID-19 (en inglés, coronavirus disease), SARS (en inglés. severe acute respiratory sindrome '[síndrome respiratorio agudo grave]), MERS (en inglés, Middle East respiratory síndrome [síndrome respiratorio de Oriente Medio]), HCov-229E (en inglés, Human Coronavirus 229E), VNi (virus Nipah);

2.2. Nombres de las enfermedades de origen no viral: ELA (esclerosis lateral múltiple), EPOC (enfermedad pulmonar obstructiva crónica), sida (síndrome de inmunodeficiencia adquirido), CPNM (carcinoma pulmonar no microcítico); 
2.3. Léxico relacionado con la investigación clínica y el trabajo de los profesionales sanitarios

2.3.1. Léxico de laboratorio clínico: IgG (Inmunoglobulina G), IgM (Inmunoglobulina M), ARN (ácido ribonucleico);

2.3.2. Pruebas y procedimientos médicos: PCR (en inglés, polymerase chain reaction [reacción en cadena de la polimerasa]), TAC (tomografía axial computarizada);

2.3.3. Léxico epidemiológico: SiViEs (Sistema de Vigilancia en España), MoMo (Sistema de Monitorización de la Mortalidad diaria);

2.3.4. Léxico farmacéutico: DH (diagnóstico hospitalario), SPD (sistema personalizado de dosificación);

2.3.5. Áreas del hospital: UVI (Unidad de Vigilancia Intensiva), UCI (Unidad de Cuidados Intensivos);

2.3.6. Equipamiento médico: EPI (equipo de protección individual), FFP2, FFP3 (del inglés filtering facepiece [máscara protectora autofiltrante]), HEPA (del inglés High Efficiency Particulate Air [filtro de aire de alta eficiencia]);

2.3.7. Especialidades médicas y sanitarias: MIR (Médico Interno Residente), ATS (Ayudante Técnico Sanitario);

2.4. Órganos, sistemas y aparatos del cuerpo humano: SNC (sistema nervioso central), ECA (enzima convertidora de angiotensina), RAAS (del inglés reninangiotensin-aldosterone system [sistema renina-angiotensina-aldosterona]).

\subsubsection{Tipología fonológica}

En cuanto a la tipología fonológica de las siglas que funcionan en el lenguaje médico español, está basada en la teoría de Casado Velarde (Casado Velarde, 1979a y 1979b, 1985, 1999) y las recomendaciones normativas del Diccionario panhispánico de dudas. Se puede distinguir varios tipos de siglas en el plano fónico:

1) Siglas de lectura alfabética (deletreo): se pronuncia el nombre de cada una de las letras que componen la sigla. Como señala Rodríguez González, se produce «una refonemización de los grafemas tomados como letras aisladas» (Rodríguez González, 2019: 292). La lectura alfabética se explica por la combinación de sonidos de difícil pronunciación secuencial: SNS /ése-né-ése/, VIH [úve-í-áche].

2) Siglas de lectura silábica (secuencial), las siglas se leen y se pronuncian de forma integrada, como unas palabras naturales del idioma: OMS [óms], sida [sída], uci [úci]. El hecho de que se lean como palabras puede estar relacionado con la presencia de una o más vocales en su estructura, lo que hace que estas abreviaciones tengan más de una sílaba y sean más fáciles de leer ${ }^{5}$.

3) Siglas de lectura mixta (un segmento de la sigla se deletrea y otro se lee de manera habitual, es decir, secuencialmente): CSIC [ $\theta$ é-sik]

\subsubsection{Caracterización ortográfica}

En la estructura formal de siglas y sigloides propios del lenguaje médico se incluyen a menudo los números (ISCIII < Instituto de Salud Carlos III), particularmente si se trata de préstamos ingleses que denotan distintos tipos de virus: CoV-1, CoV-2, HCov-229E, NL63, OC43, HKU1. Sin embargo, se suele prescindir de los números por

\footnotetext{
${ }^{5}$ Algunos estudiosos tratan estas creaciones como acrónimos (Casado Velarde, 1979a: 35-36; Rodríguez González, 1993: 11; Rodríguez González, 2019: 279-284).
} 
razones de comodidad y economía; se usa solo la forma alfabética donde sea posible: COVID $<$ COVID-19.

Cabe destacar que ninguna sigla hoy en día se utiliza con puntos en la escritura y también se extiende más la minusculización del cuerpo de las siglas, sobre todo en los lexemas de amplio uso en la lengua: covid < COVID.

En líneas generales podemos afirmar que, por ser un fenómeno de reciente acuñación léxica, en la ortografía de las siglas a menudo se produce «vacilación tipográfica» (Rodríguez González, 1993: 14), como se puede constatar en los siguientes casos:

1. Toda la sigla se escribe como una serie de caracteres en mayúsculas:

- Un médico, sobre el COVID-19: «Es la primera vez en mi vida que siento miedo»; (20 minutos, 16/03/2020);

- El SARS y el MERS, tan amenazantes, desaparecieron (El País, 03/06/2020).

2. Todo el cuerpo se escribe en minúsculas:

- $\quad$ [...] que cumple con todos los requisitos de seguridad que exige la covid-19 (El País, 05/06/2020).

3. Se escribe en mayúscula solo la primera letra y el resto, en minúsculas:

- El Mers apareció en Arabia Saudí en 2012 y fue muy letal (El País, 14/04/2020).

4. Se escribe un guion para separar la parte numérica de la parte alfabética de un sigloide o una sigla compuesta o para mostrar que se trata de institutos o unidades que forman parte de una estructura organizativa más amplia:

- La pandemia de SARS-CoV-2 suma cada día nuevos diagnósticos (El País, 09/04/2020);

- En este trabajo, hecho en colaboración con el Institut de Química Avançada de Catalunya (IQAC-CSIC) [...] (20 minutos, 09/06/2020).

5. El sigloide o la sigla compuesta se escribe sin guion:

- [...] principal vector de transmisión del virus SARS-Cov2 a sus familias y personas de su entorno (El País, 05/06/2020).

Rodríguez González llega a considerar, incluso, las oscilaciones individuales en la lectura de la sigla que tienen lugar debido a distintos grados de familiarización de los hablantes con la sigla en cuestión (Rodríguez González, 2019: 293). Esta teoría se corrobora por el material de nuestro corpus seleccionado, donde la escritura de la sigla puede variar de un artículo para otro en función del profesionalismo o el grado de instrucción especializada del autor ${ }^{6}$.

\subsubsection{Lexicalización de las siglas}

Entre la multitud de siglas existentes hay algunas, cuya presencia en la lengua se ha hecho tan común y corriente que no requieren ser desglosadas en sus componentes para su compresión. Estas siglas se consideran lexicalizadas. La lexicalización, o integración lingüística, es el uso de la sigla en su función nominativa, como un lexema de pleno valor, autónomo e independiente, que no depende de la secuencia sintáctica originaria. Dicho proceso tiene lugar cuando el hablante deja de ser consciente de que la unidad léxica es una formación compuesta de origen siglar y puede producirse solo en caso de que exista un uso continuo y bien amplio de la sigla.

\footnotetext{
${ }^{6}$ Notemos, además, que todos los diarios mencionados relegan la tarea de la corrección al propio periodista o autor, no a correctores profesionales. Es evidente que la existencia de correctores sirve para lograr textos coherentes y cohesionados según las normas del periódico.
} 
Se puede trazar en líneas generales las etapas del proceso de lexicalización siglar: primero, no se tiene necesidad de desglosar la sigla al leerla y recomponer el sintagma nominal originario, lo que significa que la sigla ya ha adquirido su propio significado denotativo que coincide con el de la fuente primitiva. En segundo lugar, se produce la transición de la lectura alfabética a la lectura silábica por ser más rápida. Y, finalmente, se producen cambios en la forma gráfica de la sigla: las mayúsculas se convierten en minúsculas: en una primera fase, todas salvo la inicial, y después, la sigla entera, para que se parezca más un vocablo natural, único y unitario.

Si se trata de un préstamo, el proceso de lexicalización es más rápido. Es la consecuencia lógica, pues al haberse borrado la motivación original de la sigla, los hablantes ignoran cómo se desglosa en el idioma extranjero y qué secuencia sintáctica originaria ha sido su fuente. Un testimonio evidente de esta afirmación son los ejemplos de COVID, SARS y MERS citados en el apartado anterior. A pesar de no contar con décadas de uso en el idioma, ya están en el proceso de asimilación e integración lingüística. Notemos cómo su uso con artículo las hace parecer unas auténticas palabras españolas, aún más si se utilizan con la inicial en mayúscula y el resto en minúsculas, con lo que se acomodan a la norma ortográfica de los nombres propios en el idioma español.

\subsubsection{Caracterización morfosintáctica}

En la última etapa de la lexicalización siglar se puede hablar de la aparición de un nuevo lexema que forma parte del sistema de la lengua, con sus peculiaridades gramaticales; en particular, las categorías de género y número.

De acuerdo con el Diccionario panhispánico de dudas, la sigla adopta el género de la palabra nuclear de su base sintagmática, que en la mayoría de los casos es el sustantivo; y por tratarse de un sintagma nominal ocupa el primer lugar en la secuencia sintagmática: la OMS < la Organización Mundial de Salud), el CCAES < el Centro de Coordinación de Alertas y Emergencias Sanitarias.

Sin embargo, son frecuentes ciertas incongruencias gramaticales debido a la poca familiarización del autor con el ámbito del que escribe:

- [...] hay uno, que es el que indica una infección reciente, el IgM, que parece tener una reacción cruzada importante con factores reumatoides (El Mundo, 18/05/2020). Según el Diccionario de la lengua, la palabra "inmunoglobulina" es de género femenino y debería, por tanto, no solo llevar el artículo femenino "la", sino también seguir las reglas de uso de pronombres para sustituir al sustantivo correspondiente.

- [...] obligaba a equiparse con indumentaria especial y especifica como la EPI (El Mundo (20/03/2020). El núcleo del sintagma, que determina sus propiedades morfológicas, es de género masculino (equipo de protección individual) y debería llevar el artículo masculino "el".

La omisión puntual del artículo se explica, tal vez, por el hecho de que las siglas no han perdido del todo su identidad de nombres propios en la consciencia lingüística de los hablantes, con lo cual anotamos también los usos de las siglas sin artículo: Se dan en algunos pacientes graves, los que han estado en $U V I^{7}[\ldots]$ ( 20 minutos, 12/05/2020)

Se producen múltiples incorrecciones gramaticales a la hora de formar el plural de las siglas. A pesar de la recomendación del $\mathrm{DPD}^{8}$, se da el uso incorrecto de la -s final, como se evidencia en las siguientes muestras extraídas de los periódicos:

\footnotetext{
${ }^{7}$ Es llamativo que ese diario siga utilizando UVI, en vez de UCI, mucho más común en la actualidad.

${ }^{8}$ Por considerarse un anglicismo gráfico.
} 
- [...] hospitales desbordados, UVIs improvisadas en los pasillos (El País, 10/03/2020);

- La ocupación de mayores de 70 años en las UCIS fue la mayor de Europa ( $E l$ País, 11/06/2020);

- [...] aunque no tuvieran material de protección, ni camas, ni ucis suficientes [...] (20 minutos, 04/06/2020).

Según nuestras indagaciones y basándonos en el corpus seleccionado, se puede destacar las siguientes funciones sintácticas que realizan las siglas:

1. Sujeto:

- En 2020, la covid-19 le ha colocado a él al borde de la muerte (El País, 03/06/2020);

- Aunque los datos son limitados, la Aemps ha reconocido que [...] (El Mundo, 21/05/2020);

2. Parte del predicado nominal:

- [...] las urgencias que llegaban eran casi exclusivamente covid (El País, 07/06/2020);

- [...] no están consideradas EPI (El Mundo, 11/05/2020);

3. Complemento directo:

- [...] permite identificar el ARN viral (El Mundo, 20/03/2020);

4. Complemento preposicional:

- [...] Consejo General de COF (El Mundo, 24/06/2019);

- [...] inmunidad de la población española frente a la COVID-19 (20 minutos, 16/03/2020);

- minimizar las posibilidades de contagio por Covid-19 [...] (ABC, 13/06/20202)

5. Aposición desempeñando una función adjetiva:

- suplemento Covid $(A B C, 11 / 06 / 2020)$;

- servicio Covid (20 minutos, 09/06/2020);

- tasa covid (El País, 11/06/2020);

- camas UCIs (20 minutos, 09/06/2020).

Hay manifestaciones de que las siglas lexicalizadas pueden acompañarse de pronombres posesivos:

- Ha venido a buscarme Rafa con su EPI (El País, 03/06/2020)

Es interesante que las siglas muestren un patrón de comportamiento elíptico similar al de una estructura lingüística que entre los estudiosos recibe el nombre de "truncamiento", "supresión”, “elipsis léxica” o "univerbación” (Rodríguez González, 2019). Se trata de expresiones del tipo de (máquina) lavadora, donde uno de los elementos semánticamente muy próximos del sintagma originario pasa a representar, metonímicamente, el significado del sintagma entero. Dicha transposición de significado se ilustra en los siguientes ejemplos, donde la sigla UCI en realidad denota a los pacientes que requieren cuidados intensivos:

- Durante semanas los datos de hospitalizados y UCI habían sumado cosas diferentes según la comunidad [...] (El País, 21/06/2020);

- Todavía esta semana seguía sin recuperar las cifras de hospitalizados, UCI y fallecidos (El País, 21/06/2020).

\subsubsection{Préstamos siglares}

La proliferación de siglas extranjeras en los textos médicos de la prensa digital se debe a la orientación anglocéntrica de todo lenguaje científico. En el español se muestra 
una marcada tendencia a traducir y asimilar (“españolizar") las siglas prestadas. La traducción del sintagma originario al español se refleja en el aspecto formal de la sigla, cambiando el orden de los grafemas iniciales que la integran: SIDA (síndrome de inmunodeficiencia adquirida) sustituye AIDS; VIH (virus de inmunodeficiencia humana) sustituye HIV. Sin embargo, las siglas extranjeras pueden estar sujetas a tales cambios solo en el caso de su amplia difusión y frecuencia elevada de circulación en la lengua española.

Si la sigla se usa en el texto por primera vez y no está tan consolidada ni es bien conocida para que la mayoría de los lectores la interpreten fácilmente, el autor normalmente indica el sintagma originario; $y$, por tratarse de una sigla de origen extranjero, se ofrece su traducción o explicación. A menudo en los nombres de los organismos oficiales se utiliza la forma abreviada inglesa, sin embargo, el sintagma que ha motivado esta sigla se explicita y se traduce al español: IDF (Federación Internacional de Diabetes), GAVI (Alianza Mundial para la Inmunización y la Vacunación). Sin embargo, hay autores que prefieren incluir el sintagma originario tomado directamente del inglés sin ninguna traducción ni explicación: NAFA (National Air Filtration Association).

A menudo la sigla extranjera se presenta sin traducción, ni explicación, probablemente, porque el sintagma del que procede se conozca bien en el mundo profesional o por formar parte de terminología internacional: fármacos antihipertensivos inhibidores de RAAS $(A B C, 05 / 06 / 2020)$.

Nos han llamado la atención las discrepancias gramaticales en torno al género del préstamo inglés COVID. En los textos periodísticos escritos se puede encontrar tanto los ejemplos de uso del artículo femenino, probablemente, por asociación con la palabra "enfermedad", como del artículo masculino asociado con la palabra "virus":

- Así funciona la vacuna contra la Covid-19 de Oxford (El Mundo, 15/06/2020);

- Una pediatra con síntomas del Covid-19 (20 minutos, 16/03/2020).

Las siglas inglesas PCR, FFP2 se comportan de manera similar y se usan con el artículo femenino "la" por razones semánticas asociándose con las palabras españolas "prueba" y "mascarilla", respectivamente:

- Me voy a hacer la PCR (El País, 03/06/2020).

- Eso quiere decir que no es una FFP2 pero sí un modelo equivalente [...] (El Mundo, 11/05/2020).

A nivel morfosintáctico, los préstamos tienden a desempeñar las mismas funciones en la oración que las siglas castellanas. La principal cuestión que merece una atención especial tiene que ver con el uso de los préstamos como aposiciones especificativas pospuestas al sustantivo y su consecuente adjetivación:

- filtros HEPA (El Mundo, 07/06/2020);

- filtro FFP2 y FFP3 (El Mundo, 21/05/2020);

- test PCR (El País, 05/06/2020);

- inhibidores RAAS o inhibidores no RAAS ( $A B C, 05 / 06 / 2020)$.

\subsubsection{Derivación}

Uno de los testimonios de que las siglas forman parte del sistema de la lengua española y, por tanto, obedecen sus leyes, es la creación de derivados siglares. En el corpus analizado hemos destacado los procedimientos derivativos más característicos del lenguaje médico en los textos periodísticos: 1) prefijación; 2) composición por aglutinación. 
La derivación por prefijación se produce cuando a la sigla se añade un prefijo:

- POST-COVID (El Mundo, 01/05/2020) [también escrito como poscovid] (20 minutos, 10/06/2020);

- [...] ya con los protocolos de aforo anticovid en marcha (El País, 07/06/2020).

Existen vacilaciones en cuanto a la escritura de los derivados formados por prefijación: los prefijos se escriben unidos a su base, separados de ella o seguidos de un guion. Según la Nueva gramática de la lengua española, los elementos como "anti" son prefijos separables, por eso se recomienda escribirlos seguidos de un guion cuando se añaden a una sigla (Nueva gramática de la lengua española, 2010: 178). Sin embargo, se puede observar en los ejemplos arriba citados que esta norma rara vez se cumple.

La derivación por composición también produce abreviaciones compuestas: IDAEA-CSIC (Instituto de Diagnóstico Ambiental y Estudios del Agua), SARS-CoV-2.

Las siglas pueden integrarse en compuestos sintácticos formados por la unión de dos elementos en su significado, donde los elementos se mantienen separados por un guion en la escritura:

- estudio 'Covid-Piel' (20 minutos, 30/04/2020);

- ENE-COVID (Estudio Nacional Epidemiológico de la infección por SARSCoV2) (20 minutos, 22/04/2020);

$[\ldots]$ soluciones «milagrosas» bajo la etiqueta "Covid-free" $(A B C, 12 / 06 / 2020)$.

\section{CONCLUSIONES}

Los cambios que se evidencian en la esfera de formación de palabras son un fiel reflejo de una tendencia general a la economía de los medios lingüísticos, que se ve favorecida por un proceso de democratización de la lengua: los periodistas contemporáneos no siempre siguen las normas de los libros de estilo para flexibilizar y agilizar el uso de la lengua, por un lado, y alcanzar la máxima expresividad, por otro.

Los datos procedentes del análisis del corpus seleccionado de la prensa actual ponen de manifiesto que el progreso científico-técnico sigue contribuyendo al enriquecimiento del vocabulario del idioma español con nuevas denominaciones y que, además, los periodistas siguen buscando las estrategias de expresión más eficaces por lo que recurren al potencial expresivo de las abreviaciones para conseguir la proximidad y la atención de los lectores.

Los resultados de nuestra investigación permiten hacer una suposición sobre la existencia de unas bases cognitivas específicas del mecanismo de abreviación como una forma en que el ser humano toma conciencia de la realidad y la refleja en el habla. El hecho de que un fenómeno frecuentemente referido en los periódicos - representado por una larga palabra o sintagma que entorpece su uso - se abrevie y, con el tiempo, empiece a utilizarse como una abreviación, evidencia que se produce una automatización de la actividad cognitiva referente a un área concreta de la realidad. Se establecen unas asociaciones cognitivas fijas, estables y repetidas entre un objeto real y su representación abreviada, sirviendo, por tanto, a los fines de economía cognitiva y lingüística.

Creemos haber mostrado sobradamente que, al surgir como fruto del estilo científico y administrativo, las abreviaciones tienen su propia identidad lingüística y pasan a formar parte del repertorio de recursos estilísticos y expresivos de la lengua española.

\section{REFERENCIAS BIBLIOGRÁFICAS}

Alarcos Llorach, Emilio. 1977. «Lenguaje de los titulares». En Lenguaje en periodismo 
escrito, ed. Fernando Lázaro Carreter. Madrid: Fundación Juan March.

Aleza Izquierdo, Milagros (coord.). 2006. Lengua española para los medios de comunicación: usos y normas actuales. Valencia: Tirant lo Blanch.

Almela Pérez, Ramón. 1999. Procedimientos de formación de palabras en español. Barcelona: Ariel.

Alvar Ezquerra, Manuel. 1996. La formación de palabras en español. Madrid: Arco Libros.

Alvar Ezquerra Manuel, y Aurora Miró Domínguez. 1983. Diccionario de siglas y abreviaturas. Madrid: Alhambra.

Álvarez de Miranda, Pedro. 2007. Acrónimos, acronimia: revisión de un concepto. Alicante: Biblioteca Virtual Miguel de Cervantes. http://www.cervantesvirtual.com/nd/ark:/59851/bmckd299.

ASALE. Diccionario de la Real Academia Española (23ª edición). http://lema.rae.es/drae/

ASALE. Diccionario panhispánico de dudas. ASALE. https://www.rae.es/dpd/

ASALE. Nueva gramática de la lengua española. 2010. Real Academia de la Lengua. Madrid: Espasa.

Casado Velarde, Manuel. 1979a. «La creación léxica por acronimia en español actual». Español Actual, 35/36: 35-43.

Casado Velarde, Manuel. 1979b. «Creación léxica mediante siglas». Revista Española de Lingüística, 9 (1): 67-89.

Casado Velarde, Manuel. 1985. Tendencias en el léxico español actual. Madrid: Coloquio.

Casado Velarde, Manuel. 1999. «Otros procesos morfológicos: acortamientos, formación de siglas y acrónimos». En Gramática descriptiva de la lengua española, ed. Ignacio Bosque y Violeta Demonte. Madrid: Espasa-Calpe.

Grijelmo, Álex. 2008. El estilo del periodista. Madrid: Taurus.

Hernando Cuadrado, Luis Alberto. 1996. «Sobre la formación de palabras en español». En Actas del VII Congreso Internacional de ASELE Lengua y Cultura en la Enseñanza del Español a Extranjeros. http://cvc.cervantes.es/ensenanza/biblioteca_ele/asele/pdf/07/07_0255.pdf.

Hurtado González, Silvia. 2003. El uso del lenguaje en la prensa escrita. Valladolid: Secretariado de Publicaciones e Intercambio Editorial, Universidad de Valladolid.

Lang, Mervin. 1992. Formación de palabras en español. Morfología derivativa productiva en el léxico moderno. Madrid: Cátedra.

Martín Camacho, José Carlos. 2007. «La creación de términos científicos mediante procedimientos no morfemáticos». Anuario de estudios filológicos, 30: 239254.

Martínez Agudo, Juan de Dios. 2000. «La economía lingüística derivada de la formación periodística». Puertas a la lectura, 11: 80-85.

Martínez de Sousa, José. 1978. Diccionario internacional de siglas. Madrid: Pirámide.

Merriam-Webster Dictionary. https://www.merriam-webster.com/

Muñiz Chacón, Carmen. 1990. «Retórica en los titulares de prensa». Investigaciones semióticas, III(2): 215-222.

Oliva-Marañón, Carlos. 2011. «La creación léxica mediante siglas: un recurso de condensación expresiva en la prensa digital». Revista de Comunicación Vivat Academia, 117: 63-76.

Rodríguez González, Félix. 1989. «Los cruces léxicos en el ámbito político-periodístico». Verba, 16: 357-386.

Rodríguez González, Félix. 1991. Derivados de siglas de carácter político. Prensa y lenguaje político. Madrid: Fundamentos. 
Rodríguez González, Félix. 1993. «Las siglas como procedimiento lexicogenésico». ELUA: Estudios de Lingüistica, 9: 9-24.

Rodríguez González, Félix. 2012. «Origen y evolución de las siglas». En Estudios de lingüística española: homenaje a Manuel Seco, ed. Félix Rodríguez González; Manuel Seco Reymundo. Publicaciones de la Universidad de Alicante.

Rodríguez González, Félix. 2019. «Taxonomía de las abreviaciones y de la siglación: revisión crítica y propuestas terminológicas». Revista Española de Lingüistica, 49: 267-312.

Rodríguez González, Félix y José Antonio Sánchez Fajardo. 2018. «Morpho-syntactic variations in English and Spanish clipped words: a contrastive study». Zeitschrift für romanische Philologie, 134(3): 734-760.

Romero Gualda, María Victoria. 1993. El español en los medios de comunicación. Madrid: Arco Libros.

Rosell, Avenir. 1967. Escritura de formas siglares. Montevideo: Imp. Letras.

Sanmartín Sáez, Julia. 2019. «Neología y lematización: acortamientos y siglas en los diccionarios de español». Revista de Lexicografia, XXV: 79-101.

VV.AA. s.a. Diccionario médico-biológico, histórico y etimológico. https://dicciomed.usal.es/ 